\title{
Middle management's role in strategy implementation projects: a behavioral analysis
}

\author{
Jan KIEHNE \\ The Bucharest University of Economic Studies, Bucharest, Romania \\ jan.kiehne@gmail.com \\ Ioana CEAUSU \\ The Bucharest University of Economic Studies, Bucharest, Romania \\ Ann-Katrin ARP \\ The Bucharest University of Economic Studies, Bucharest, Romania \\ Timm SCHÜLER \\ The Bucharest University of Economic Studies, Bucharest, Romania
}

\begin{abstract}
The ability of businesses to adapt their strategy quickly and effectively to the changing environment in an ever more globalized economy has become one of the key success factors for sustainable competitive advantage and above average economic returns. Success factor oriented research has identified a number of obstacles that hinder effective strategy implementation and there is growing support in the research community that the behavior of middle management, who frequently take on key positions in strategy implementation projects, is of significant importance for success or failure. However, most studies have looked at the issue from a descriptive perspective, only few have analyzed the role of middle management from a normative viewpoint. This study builds upon Porter and Lawler's qualitative model of managerial motivation which is transformed into a quantitative principal agent model to analyze the behavior of middle managers as key actors in executing strategic projects. The analysis highlights the necessity of adequate incentive systems for strategy implementation projects. Further, the importance of managing both objective and perceived implementation risk is demonstrated. Finally, the authors suggest distinguishing obstacles of strategy implementation into process issues and behavioral issues.
\end{abstract}

Keywords: strategy implementation, obstacles, middle management, risk, motivation, behavior.

\section{Introduction}

On average, companies realize only $63 \%$ of the financial performance their strategies promise (Mankins \& Steele, 2005) and up to two out of three strategies never get fully implemented (Johnson, 2005). Success factor research has identified numerous obstacles to successful strategy implementation such as lack of top management attention, unclear strategic priorities, poor vertical communication, poor coordination across functions and organizational borders, and inadequate lower-level leadership skills (Beer \& Eisenstat, 2000). Middle level managers are key players for making strategy work. They are both a source of knowledge for senior management to develop and formulate a strategy as well as a vital element in selling high level strategic plans to lower levels in the organization and even translating it and putting it into context so that working level employees can make sense of high level strategic directions (Huy, 2001). Hence, getting middle managers on 
board and motivating them to actively support strategic change does positively influence chances of success.

This article looks at the factors that drive motivation of middle managers within strategy implementation projects. Based on Porter and Lawler's model of managerial motivation (Porter \& Lawler, 1968) the authors present a quantitative decision model which is used to analyze the impacts of organizational and project parameters on middle manager's behavior. These theoretically derived insights are compared against empirically reported obstacles of strategy execution. One key aspect the authors will demonstrate is that in order to maximize likelihood of success for a strategic initiative to be implemented leaders in charge should pay attention to both objective and subjective (i.e. perceived) risk associated with the project. Or in other words, it is not sufficient to have a good plan in place and provide adequate resources to execute a strategy but it is key critical that middle managers who are supposed to lead the change process understand and believe in the plan. Further, the authors will argue that there is a behavioral dimension in strategy implementation which adds to and reinforces effects of (hard) process factors.

\section{Literature review}

For this study, we view strategy as "the set of decisions and actions resulting in the formulation and implementation of strategies designed to achieve the objectives of the organization" (Pearce \& Robinson, 2000). While today, it is largely undisputed that, in order to ensure that a formulated strategy can also be executed successfully, aspects of implementation already should be considered during the phase of strategy formation (Hambrick \& Cannella, 1989) for didactic reasons we consider strategic change as a sequential, planned process to optimize performance by establishing a fit between the firm and its environment through creation and implementation of a strategic vision (Rajagopalan \& Spreitzer, 1997).

Descriptive, empirical studies have identified numerous obstacles to successful strategy implementation like inadequate and ineffective senior management support and/or style, unclear strategy and conflicting priorities, poor vertical communication, poor coordination across functions, businesses or borders, inadequate down-the-line leadership skills and development, insufficient time and resources allocated to the project, insufficient planning, insufficient information systems, and occurrence of unexpected major internal or external problems (Al-Ghamdi, 1998; Alexander, 1985; Beer \& Eisenstat, 2000). More refined research has looked at the moderating effects of organizational variables on strategy execution processes like size and environmental complexity which tend to be positively related to number of organizational members being engaged in the implementation process (Harrington, 2006). Typologies of implementation tactics have been defined to help practioners understand under which scenarios certain implementation approaches work best (Bourgeois \& Brodwin, 1984; Lehner, 2004; Nutt, 1989; Slevin \& Pinto, 1987).

Particular interest in the efforts to understand strategy implementation processes have been directed to the group of middle management as key players in operationalizing and selling a strategy to lower levels of the organization (Herzig \& Jimmieson, 2006; Salih \& Doll, 2013). During the strategy formulation phase middle managers can serve as valuable sources of information for top management (Huy, 2001). They can use their "weight" in an organization (their social capital as opposed to formal authority) to both help or hinder 
execution of strategic initiatives (Ahearne, Lam, \& Kraus, 2014). A participative management style by top leaders towards middle management has been found to positively impact implementation results in many cases (Salih \& Doll, 2013), particularly for innovative projects (Kanter, 1982). Such leadership style also has positive impacts on building consensus on the strategy to be implemented which tends to improve implementation results (Ho, $\mathrm{Wu}, \& \mathrm{Wu}, 2014)$. However, too much participation creates more issues than helping (Ahearne et al., 2014) and in certain situations even autocratic leadership styles can be the approach of choice, especially when the change has to happen under great time pressure or when no or only limited expertise about the new strategic direction exists in the organization (Nutt, 1989).

Most studies on middle management's role in the strategy process are descriptive in nature with only few trying to understand and prescriptively model middle management behavior. One of these normative studies discusses how middle managers may behave in an implementation project when looking after maximizing their own well-being, i.e. what organizational variables potentially lead to middle managers actively or passively objecting strategic change efforts (Guth \& MacMillan, 1986). Applying expectancy theory, Guth and MacMillan derived three potential sources for middle managers to not support the implementation of a strategy formulated by their senior management: 1) they don't believe their personal effort will lead to a satisfactory personal performance, 2) they don't believe that a successful personal performance will lead to the desired organizational outcome, 3) the desired personal outcome does not satisfy their personal needs (Guth \& MacMillan, 1986). These theoretically derived findings were empirically confirmed (Judge \& Stahl, 1995). The article presented here builds upon and extends the normative research approach of Guth and MacMillan.

\section{Research Methodology}

This study is normative in nature, aiming at analyzing and interpreting the parameters that influence managers' behavior in Strategy Implementation scenarios and better understanding the fundamental issues behind empirically reported implementation obstacles.

\section{Theoretical Basis}

Theoretical basis is Lyman Porter and Edward Lawler's model of managerial motivation (see figure 1). In line with Vroom's expectancy theory (Vroom, 1964) it says that a manager's decision on the effort he puts into a task depends on his expectation that such effort will lead to an organizationally desired outcome, how likely he thinks it is that he will be rewarded for such outcome, and how valuable such potential rewards would be for him. Extending basic expectancy theory it further states that the manager's personal characteristics and skills (abilities and traits) and his understanding of what is required to get the job done will impact overall organizational performance which in turn may trigger intrinsic and/or extrinsic rewards for the manager. Contingent to his personal preferences these potential rewards have a certain value for him and lead to a certain level of (expected) satisfaction. The model allows for learning insofar as realized satisfaction in the past impact the value the manager assigns to potential future rewards and the experienced causal connection between accomplished performance and rewards received shape his expectations regarding how likely it is that certain performance levels will lead to certain 
levels of rewards. Two sources of uncertainty are reflected in the model. First, the uncertainty that certain effort will lead to certain performance. Second, that certain performance will result in certain rewards.

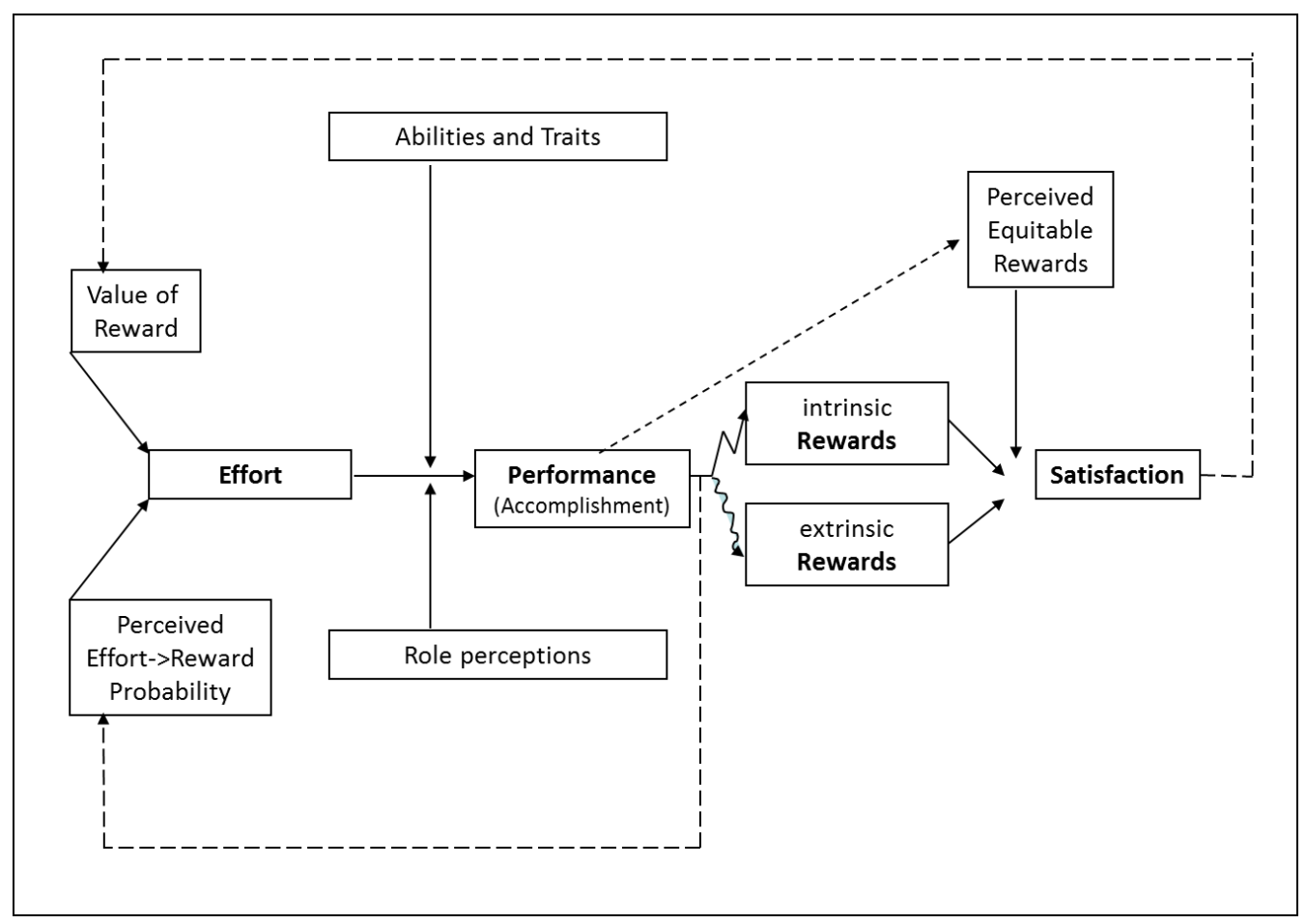

PICBE $\mid 542$

Figure 1. Model of Managerial Motivation

Source: (Porter \& Lawler, 1968).

In order to enable a theoretical analysis we transform the qualitative Porter and Lawler model into a quantitative Principal-Agent-model. Particularly, we tighten Porter and Lawler's rather broad assumption regarding the manager's preference order to requiring that the manager decides according to the Bernoulli principles (for a description of the Bernoulli principle see for example (Laux, 2007)) and, after re-arranging and grouping the elements of the model (see figure 2), make following additional assumptions: 


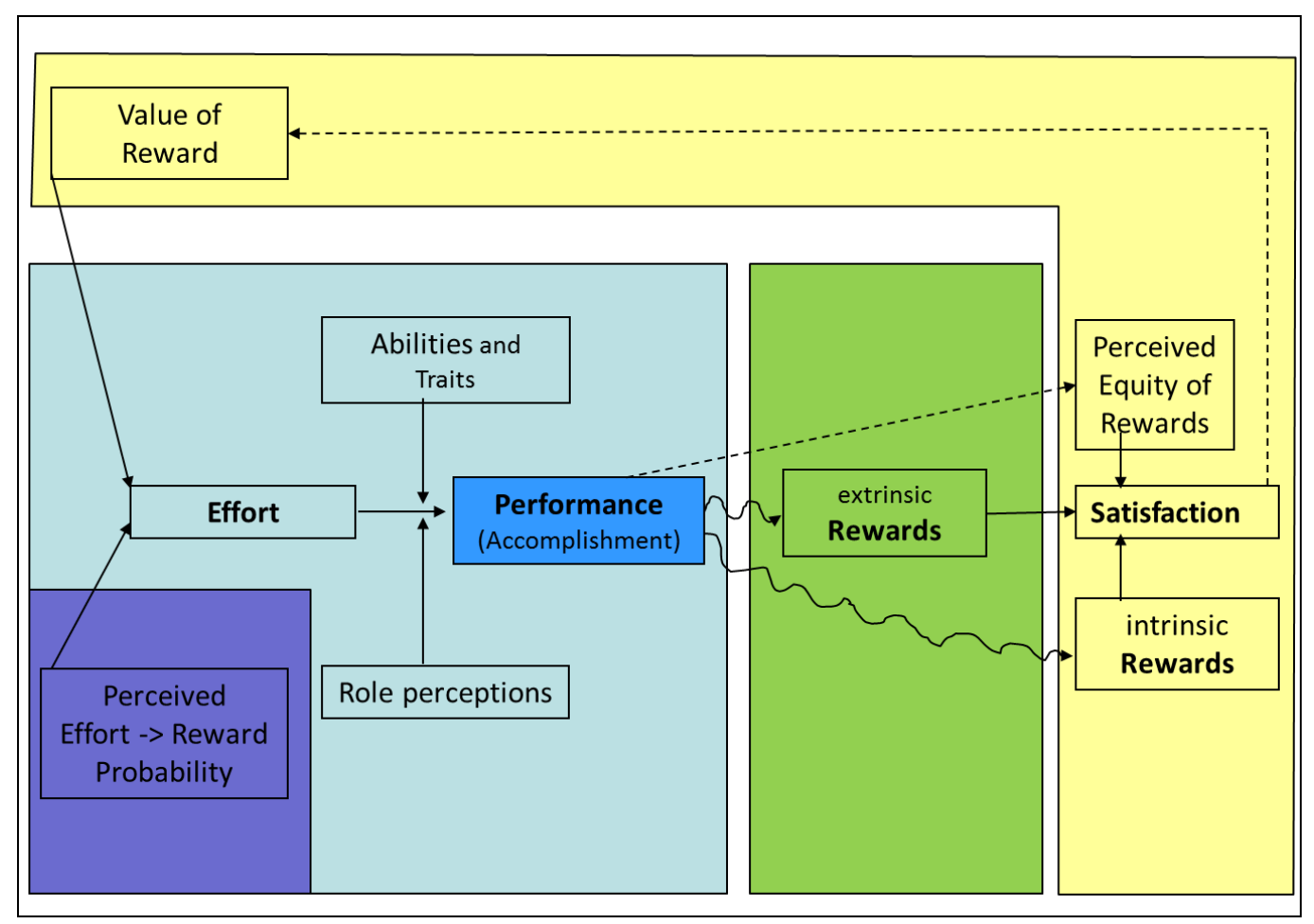

Figure 2, Model of Managerial Motivation

PICBE | 543

Source: Authors' own research.

First (yellow area), the level of satisfaction a manager derives from extrinsic and intrinsic rewards and the value he assigns to such rewards can be described by a von Neumann-Morgenstern utility function. Second (green area), the uncertainty that a certain performance leads to certain extrinsic rewards is removed by introducing a contract between the manager and the owner of the strategy which clearly links rewards to realized outcome. Third (light blue area), the transformational relationship between effort put into a performance oriented task, including the mediating effects of the manager's skills and personality as well as his understanding of the job at hand, and the outcome of such effort (dark blue area) can be expressed (or at least approximated) by mathematical InputOutput-rules. Fourth (purple area), the uncertainty that certain level of effort will lead to certain rewards can be expressed by a probability distribution over the Input-Output relation (please note that by introducing the contract one of the sources of uncertainty in the original model has been removed). As in the original Porter-Lawler model the effort of the manager cannot be directly observed by the strategy owner. In the following section we mathematically model the modified Porter-Lawler model as a LEN-P-A-model (Laux, 1990). 


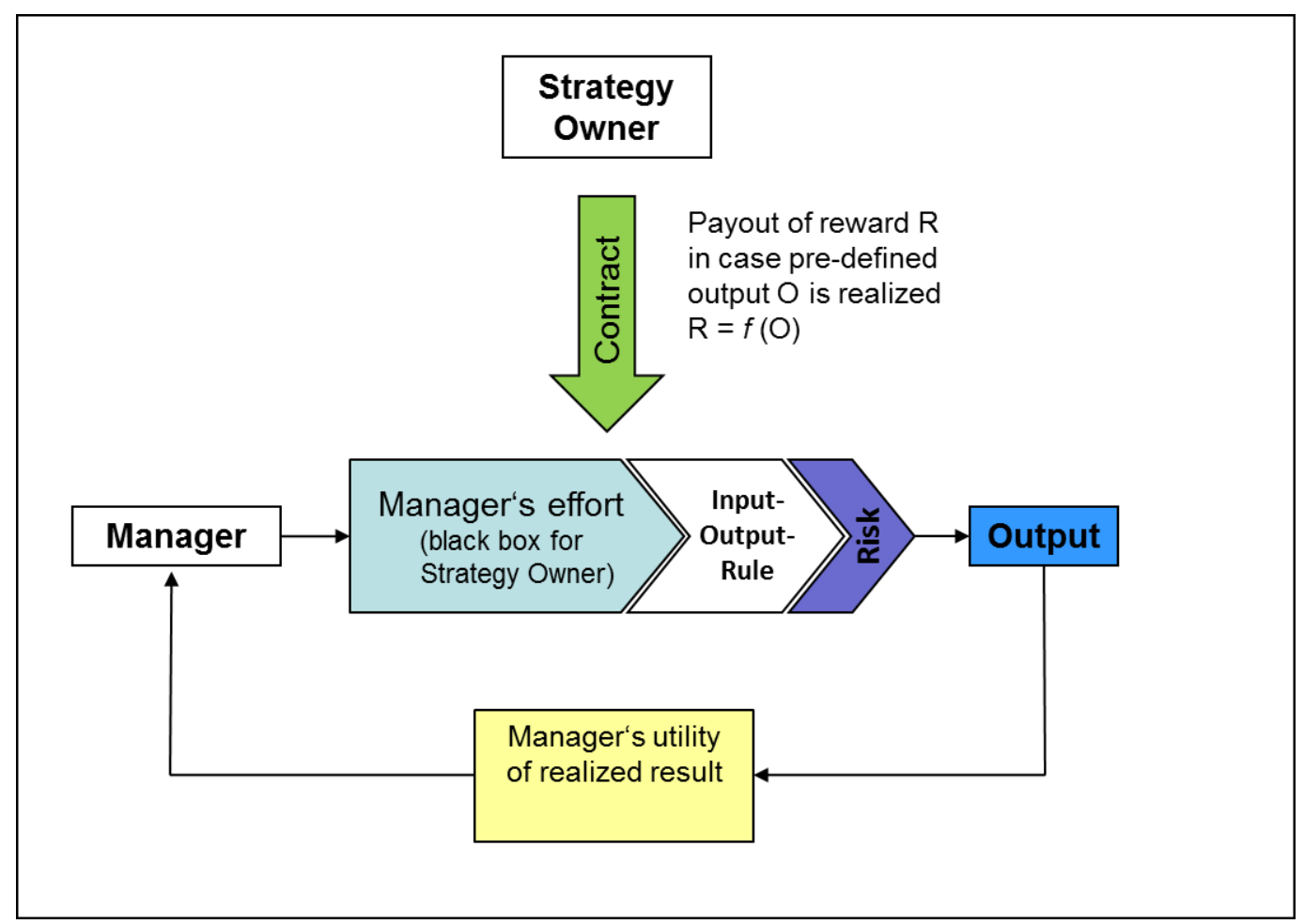

Figure 3, Modified Porter-Lawler Model

Source: Authors' own research.

\section{The Analytical Model}

The strategy owner delegates implementation of the strategy to a middle manager. The owner is not able to observe the manager's activities, especially not the directed effort the manager puts into the task. Output is defined as the degree to which the strategy is implemented, can be cardinally measured, depends on the effort of the manager, is impacted by internal and external risk factors (risky implementation environment) and assumes values between 0 (not implemented) and 100 (fully implemented). The strategy owner knows that higher effort on behalf of the manager increases expected output without shifting the upper and lower boundaries of possible outcomes. Therefore it is not possible for the strategy owner to conclude from realized output to the effort level of the manager.

It is assumed that there is a linear relationship between effort and expected output: $\mathrm{E}(\mathrm{O})=\mathrm{x} * \mathrm{I}$, with I being the manager's effort level, $\mathrm{E}(0)$ being the expected output and $\mathrm{x}$ being the "productivity" factor of the project, i.e. a constant reflecting how increased effort on behalf of the manager, ceteris paribus all other project parameters, can be expected to increase output. The output is assumed to be normally distributed with variance $\sigma^{2}$. The basic assumption is that strategy owner and manager have identical understandings regarding expected output and risk. They both know each other's utility functions. The manager has an alternative source of income with a risk-free payout of $\mathrm{C}$.

The contract between strategy owner and manager provides for fixed compensation $\mathrm{F}$ plus a variable bonus $\mathrm{f}$ times the realized degree of implementation (realized output). Total compensation of the manager equals $\mathrm{B}=\mathrm{F}+\mathrm{f} * \mathrm{O}_{\mathrm{r}}$. The manager's utility function $\mathrm{U}_{\mathrm{M}}(\mathrm{B}, \mathrm{I})=-\mathrm{e}^{-\mathrm{a}^{*} \mathrm{~B}}-\mathrm{y}^{*} \mathrm{I}^{2}$ is additively separable regarding effort $\mathrm{I}$ and compensation $\mathrm{B}$ with a being his degree of risk-averseness and y being his penalty of work factor. 
We assume that the value of the strategy for the owner increases proportionally from 0 to $100 \%$. The strategy owner is risk neutral.

\section{The Decision Problem}

Both manager and strategy owner strive to maximize their individual wellbeing, i.e. they act such that they maximize the expected value of the utility resulting from the outcome of the implementation project. In line with the Bernoulli principle this decision rule is equivalent to maximizing the certainty equivalents associated with their choices.

\section{Deriving optimal model parameters}

For the risk neutral strategy owner, his certainty equivalent equals expected net gain $\mathrm{E}(\mathrm{NG})$, i.e. the value of the strategy implemented minus the compensation paid to the manager. His target function is $E(N G)=x * I-E(B)=(1-f) * x * I-F$ (equation 1 ).

Because of his exponential, additively separable utility function and since his labor penalty is not a stochastic variable, the manager's certainty equivalent can be expressed as $\mathrm{CE}_{\mathrm{M}}(\mathrm{B}, \mathrm{I})=\mathrm{E}(\mathrm{B})-\frac{a}{2} * \sigma_{B}^{2}-\mathrm{y} * \mathrm{I}^{2}=\mathrm{F}+\mathrm{f} * \mathrm{x} * \mathrm{I}-\frac{a}{2} * \mathrm{f}^{2} * \sigma^{2}-\mathrm{y}^{*} \mathrm{I}^{2}$. Setting the first derivate with respect to effort equal to zero (as the necessary condition for a maximum) and rearranging we get the optimal effort level $I^{*}$ for the manager as $I^{*}=f * \frac{x}{2 y}$.(equation 2)

Given that the effort level chosen by the manager does not depend on F the strategy owner will set $\mathrm{F}$ as low as possible, i.e. such that the cooperation condition is just fulfilled: $\mathrm{CE}_{\mathrm{M}}=\mathrm{F}+\mathrm{f} * \mathrm{x} * \mathrm{I}-\frac{a}{2} \mathrm{f}^{2} * \sigma^{2}-\mathrm{y} * \mathrm{I}^{2}=\mathrm{C}$ (equation $3 \mathrm{a}$ ). After some rearranging we get $\mathrm{F}=\mathrm{C}-\mathrm{f}$ $* \mathrm{x} * \mathrm{I}+\frac{a}{2} * \mathrm{f}^{2} * \sigma^{2}+\mathrm{y} * \mathrm{I}^{2}$ (equation $3 \mathrm{~b}$ ). After inserting equations 2 and $3 \mathrm{~b}$ into the strategy owner's target function (equation 1), setting the first derivate with respect to f equal to zero and, again, after some rearranging we get the optimal variable compensation factor $\mathrm{f}_{\mathrm{opt}}=$ $\frac{1}{1+a * \frac{2 * y * \sigma^{2}}{x^{2}}}$. (equation 4$)$.

Inserting equations 2 and 4 into equation 3 yields for the optimal fixed compensation $\mathrm{F}_{\mathrm{opt}}=\mathrm{C}-f_{\text {opt }}^{2} *\left[\frac{x^{2}}{4 * y}-\frac{a * \sigma^{2}}{2}\right]$.

\section{Results}

The model provides some interesting insights into the drivers of implementation managers' behavior and consequences for the strategy owner.

First, the authors believe that in order to be able to manage strategy implementation there needs to be an effective incentive structure in place to motivate managers to behave in line with organizational expectations. This can be concluded directly from the Porter and Lawler model since expected rewards, moderated by factors such as abilities and traits, and role perceptions, are the key driver of motivation.

Second, the model highlights that managing implementation risk is important. While risk does not impact the effort level chosen by the manager (see equation 2) it is key critical with regard to the cooperation condition (equation 3a). Moderated by the risk-averseness factor of the manager his requested risk premium increases with higher risk by power of two. Once the incentive system has been defined any increase in risk leads to a breach of the cooperation condition, i.e. the manager would try to get out of the contract and realize his 
alternative, risk free income C. For the strategy owner this means that he would have to define the fixed portion of total manger compensation in a way that not any increase in risk would lead to a breach of the cooperation condition. In other words, the strategy owner would have to pay some sort of extra insurance premium to cope with unknown implementation risks..

Third, the authors argue that obstacles to strategy implementation have two dimensions: process issues and behavioral issues. Process issues in our context are defined as shortcomings in planning, staffing and technically running a project. Behavioral issues are related to the way people act within a given project environment. Behavioral issues come into play when initiatives directly impact the wellbeing of those involved in their implementation. In our model, effectiveness of an implementation plan is represented by the productivity factor $\mathrm{x}$. If we recall the original Porter and Lawler model, attributes impacting this factor are particularly the manager's hard and soft skills (abilities and traits) as well as his understanding of what it takes to get the job done (role perception). Not specifically shown in the Porter and Lawler model but implied by assuming that effort on behalf of the manager results in organizational performance is some sort of transition process with adequate structures and resources. If, for example, available resources were not sufficient to execute the plan in our model this would result in a lower productivity factor $\mathrm{x}$. The direct consequence of this, ceteris paribus, would be a reduction in expected output, i.e. the expected degree of implementation would be lower than originally planned for. However, an additional behavioral consequence of this would be that the manager chose a lower effort level, further reducing expected output. Thus behavioral consequences reinforce the negative effects the process issues.

Fourth and maybe most important, process issues don't even have to really exist in order to trigger behavioral issues. It is sufficient if the manger believe they are there. This aspect of objective and subjective implementation risks is not much considered in the literature on strategy implementation. For example, if the manager is of the opinion that total resources available to execute an implementation project are not sufficient (even though objectively this may not be the case) he would act as if this was true. He would decide on his effort level based upon an assumed productivity factor $\mathrm{x}_{\mathrm{sub}}<\mathrm{x}_{\mathrm{obj}}$. As a consequence, he would bring up less effort than optimal for him and also for the strategy owner, resulting in lower-than-optimal overall results. Similar effects would have doubts on behalf of the manager if he has the skills to get the job done or if he hadn't fully understood the plan to be executed. A reduced effort level and overall output may in the end even lead to a breach of the cooperation condition potentially resulting in the manager seeking to get out of the project altogether.

\section{Discussion}

Regarding the practical relevance of above results, a recent study on obstacles to strategy implementation for 172 Slovenian businesses (Čater \& Pučko, 2010) reports the lack of adequate incentive systems as the most frequently named implementation problem by the group of companies studied. Earlier studies had also identified lack of effective rewards mechanisms as implementation problems (Al-Ghamdi, 1998; Alexander, 1985) or have highlighted their importance for successful strategy implementation (Hrebiniak, 2006; Shah, 2005). 
At first glance, stressing the importance of managing implementation risk seems like stating the obvious. However, what is most important here to note is that strategy owners should focus on both objective risk factors as well as perceived risk that stem from subjective evaluation of attributes defining the implementation environment. Strong (though indirect) empirical support for this hypothesis is the fact that lack of communication is listed in numerous studies that looked at strategy implementation problems (Al-Ghamdi, 1998; Alexander, 1985; Čater \& Pučko, 2010; Hambrick \& Cannella, 1989; Heide, Grønhaug, \& Johannessen, 2002; Hrebiniak, 2006). Communication is the most important tool to remove what in financial theory is called unsystematic risk, i.e. risk that is not process-inherent and can be removed if handled appropriately. In an implementation context, this would mean to make sure everybody has the same understanding of what needs to be done to execute a strategy successfully and to get everybody to buy into and trust the implementation plan and those who provide the required resources for it.

Finally, distinguishing between process and behavioral issues in strategy implementation is meant to open up a new perspective to analyze implementation obstacles and to develop measures to avoid them. To the knowledge of the authors, only few studies have explicitly taken on this view for their analysis (e.g. Kolks, 1990). Strategy owners need to be aware that behavioral issues compound the effects of real or even only subjectively perceived process issues. Fixing the hard facts alone may not yield the desired results. It is equally important to address the soft facts and make sure all players in the project are aligned, share the same understanding and hence act based on the same assessment of all project variables.

\section{Conclusions}

The analytical approach used in this study can be criticized in many ways. For example, that people not always decide rationally in line with the Bernoulli principles or that the quantitative model presented is oversimplifying real world situations. However, the authors believe that particularly for managers the assumption of rational behavior and conscious maximization of their own well-being is realistic for most cases. And simple models may not be very "exact" but hint in the right direction, which was the present purpose.

The notion of managing objective and perceived project risk, especially through adequate communication, has direct practical relevance for strategy owners and implementers. Simply put, it isn't sufficient to set up a good plan, provide enough resources, and track performance towards established targets, owners of the process need to make sure that relevant players understand and share what has been done and needs to be done. Distinguishing between process issues and behavioral issue in strategy implementation research will hopefully be picked up by future studies which could refine the model presented here, for example by introducing alternative utility or productivity functions. Empirical research could be directed towards assessing the impact behavioral and process issues have on implementation results, potentially using replicable experiments under laboratory conditions (simulated scenarios).

\section{References}

Ahearne, M., Lam, S.K., and Kraus, F. (2014). Performance impact of middle managers' 
adaptive strategy implementation: The role of social capital. Strategic Management Journal, 35, 68-87.

Al-Ghamdi, M.S. (1998). Obstacles to successful implementation of strategic decisions: the British experience, European Business Review, 98(6), 322-327.

Alexander, L.D. (1985). Successfully implementing strategic decisions. Long Range Planning, 18(3), 91-97.

Ansoff, H. I. (1965). Corporate Strategy. New York: McGraw Hill.

Beer, M., and Eisenstat, R.A. (2000). The Silent Killers of Strategy Implementation and Learning, Sloan Management Review, 41, 29-40.

Bourgeois, L.J., and Brodwin, D.R.D. (1984). Strategic implementation: Five approaches to an elusive phenomenon. Strategic Management Journal, 5, 241-264.

Čater, T., and Pučko, D. (2010). Factors of effective strategy implementation: Empirical evidence from slovenian business practice, Journal for East European Management Studies, 15, 207-236.

Chandler, A.D. (1962). Strategy and Structure: History of the Industrial Enterprise. MIT.

Guth, W.D., and MacMillan, I.C. (1986). Strategy Implementation Versus Middle Management Self-Interest, Strategic Management Journal, 7, 313-327.

Hambrick, D.C., and Cannella, A.A. (1989). Strategy Implementation as Substance and Selling. Academy of Management Executive, 3(4), 278-285.

Harrington, R.J. (2006). Strategy Implementation Success: The Moderating Effects of Size and Environmental Complexity and the Mediating Effects of Involvement, Journal of Hospitality \& Tourism Research, 30(2), 207-230.

Heide, M., Grønhaug, K., and Johannessen, S. (2002). Exploring barriers to the successful implementation of a formulated strategy, Scandinavian Journal of Management, 18, 217-231.

Herzig, S.E., and Jimmieson, N.L. (2006). Middle managers' uncertainty management during organizational change, Leadership \& Organization Development Journal, 27(8), 628-645.

Ho, J.L.Y., Wu, A., and Wu, S.Y.C. (2014). Performance measures, consensus on strategy implementation, and performance: Evidence from the operational-level of organizations, Accounting, Organizations and Society, 39, 38-58.

Hrebiniak, L.G. (2006). Obstacles to effective strategy implementation, Organizational Dynamics, 35, 12-31.

Huy, Q.N. (2001). In praise of middle managers, Harvard Business Review, 79(72-79), 160.

Johnson, L.K. (2005). Ececute your strategy, without killing it, Harvard Business School.

Judge, W.Q., and Stahl, M.J. (1995). Middle-manager effort in strategy implementation: A multinational perspective, International Business Review, 4(1), 91-111.

Kanter, R.M. (1982). The middle manager as innovator, Harvard Business Review, 60(4), 95105.

Kolks, U. (1990). Strategieimplementierung. Dt. Univ.-Verl. Wiesbaden.

Laux, H. (1990). Risiko, Anreiz und Kontrolle. Heidelberger Lehrtexte.

Laux, H. (2007). Entscheidungstheorie, 7., überarbeitete und erweiterte Auflage. Berlin Heidelberg.

Lehner, J. (2004). Strategy Implementation Tactics as Response to Organizational, Strategic, and Environmental Imperatives, Management Revue, 15, 460-480.

Mankins, M.C., and Steele, R. (2005). Turning great strategy into great performance, Harvard Business Review, 2607. 
Mintzberg, H. (1978). Patterns in strategy formation, Management Science, 24(9), 934-948. Mintzberg, H., and Waters, J.A. (1985). Of Strategies, Debilberate and Emergent, Strategic Management Journal, 6(3), 257-272.

Nutt, P.C. (1989). Selecting tactics to implement strategic plans, Strategic Management Journal, 10(2), 145-161.

Pearce, J.A., and Robinson, R.B. (2000). Strategic management: Formulation, implementation,

PICBE | 549 and control. Chicago, Illinois: Irwin.

Porter, L.W., and Lawler, E.E. (1968). Management attitudes and performance. Homewood IL.: Richard D. Irwin Company.

Rajagopalan, N., and Spreitzer, G. M. (1997). Toward a Theory of Strategic Change: a MultiLens Perspective and Intregrative Framework, Academy of Management Review, 22(1), 48-79.

Salih, A., and Doll, Y. (2013). A Middle Management Perspective on Strategy Implementation, International Journal of Business and Management, 8.

Shah, A.M. (2005). The Foundations of Successful Strategy Implementation: Overcoming the Obstacles, Global Business Review, 6(2), 293-302.

Slevin, D.P., and Pinto, J.K. (1987). Balancing strategy and tactics in project implementation, Sloan Management Review, 29(1), 33-41.

Vroom, V.H. (1964). Work and motivation. New York: Wiley. 